\title{
Sputum production in chronic cough increases the probability of asthma: a cross-sectional questionnaire study
}

\section{To the Editor:}

Cough is the most common symptom leading people to seek medical attention and, therefore, its clinical management is of fundamental importance. Management of chronic cough relies on identification and treatment of the background disorder maintaining the cough. Asthma, upper airway cough syndrome (UACS; previously called postnasal drip syndrome or chronic rhinosinusitis) and gastro-oesophageal reflux disease (GORD) are the most common background disorders in chronic cough [1].

The extremely high prevalence of cough indicates that its management must usually take place in primary healthcare, where the diagnostic resources are often limited. It would be useful if the characteristics of cough could aid in predicting the most probable cough background disorder. However, they are usually not considered useful in this respect [2]. Cough is often classified as "productive" or "nonproductive", according to the presence or absence of sputum production. Sputum production is common in chronic bronchitis, bronchiectasis, cystic fibrosis and chronic respiratory infections [3]. In the present study, we investigated whether sputum production would be associated with asthma, UACS or GORD among subjects with chronic cough.

This was a cross-sectional study among public service employees of two middle-sized towns in central Finland, altogether 13980 employees. Details of the study have been described earlier [4]. An electronic questionnaire was sent via e-mail to the participants, which included 80 questions with special attention to cough and the cough background disorders. The subjects with current cough filled in the Leicester Cough Questionnaire (LCQ) [5]. The study was approved by the Ethics Committee of Kuopio University Hospital (289/2015).

Chronic cough was defined as current cough with $\geqslant 8$ weeks' duration. Sputum production was defined as answer alternatives 1-4 to the LCQ question "In the last 2 weeks, have you been bothered by sputum (phlegm) production when you cough?" The answer alternatives were: 1) every time, 2) most times, 3) several times, 4) sometimes, 5) occasionally, 6) rarely, and 7) never. The cut-off value of 4 was chosen because it distinguished best the subjects with and without chronic bronchitis, as defined by the Medical Research Council [6], when utilising the receiver operating characteristic curve. Current asthma was defined as a doctor's diagnosis of asthma and wheezing during the last 12 months. Chronic rhinitis was defined as either nasal blockage or nasal discharge (anterior or posterior nasal drip) and either facial pain/pressure or reduction/loss of smell for $>3$ months [7]. UACS was defined as chronic rhinitis plus current chronic cough. GORD was defined as either a doctor's diagnosis of GORD or heartburn and/or regurgitation on at least 1 day per week during the last 3 months [8]. The number of background disorders was calculated as the sum of current asthma, UACS and GORD. Unexplained chronic cough indicated an absence of all of these, as well as an absence of a doctor's diagnosis of COPD (which was present in just four subjects). Chi-squared tests and logistic regression analysis were applied when appropriate.

The response rate was $26.4 \%$ (3697 subjects). The proportion of missing values was $<1 \%$ in all questions except those about family income (2.5\%) and acetylsalicylic acid intolerance (1.4\%). The present analysis focused on

@ERSpublications

Sputum production may suggest asthma as the most probable background disorder maintaining the cough https://bit.ly/2Qk8aar

Cite this article as: Koskela HO, Lätti AM. Sputum production in chronic cough increases the probability of asthma: a cross-sectional questionnaire study. ERJ Open Res 2021; 7: 00086-2021 [https://doi.org/10.1183/23120541.00086-2021]. 
the 415 subjects who suffered from current chronic cough. Their mean \pm SD age was $50.5 \pm 10.0$ years, with $83 \%$ females. Of them, 215 (51.8\%) reported sputum production. There were 102 subjects with current asthma, 157 subjects with UACS, and 113 subjects with GORD. There were 186 subjects with one, 69 subjects with two, and 16 subjects with three background disorders. In addition, there were 144 subjects with unexplained chronic cough. Among subjects with current asthma, UACS, GORD and unexplained chronic cough, the prevalence of sputum production was $71.6 \%, 56.1 \%, 55.8 \%$ and $41.7 \%$, respectively $(\mathrm{p}<0.001, \mathrm{p}=0.18, \mathrm{p}=0.32$ and $\mathrm{p}=0.003$, when compared with subjects without the disorder, respectively). The prevalence of current smoking was low $(8.6 \%)$, and lower among the subjects with GORD than among the rest of the subjects $(\mathrm{p}<0.019)$. Table 1 shows the results of the logistic regression analyses of the associations of the background disorders with sputum production, adjusted for current smoking, a well-known cause for sputum production.

The present analysis in a large population-based sample demonstrates that the presence of sputum production in chronic cough increases the probability of current asthma by three-fold. Another large population-based study corroborates this finding [9]. In that study, 59\% of subjects with asthma and chronic cough reported sputum production, significantly more often than other subjects with chronic cough. Previous studies also reveal other typical characteristics of cough in asthma. It is associated with nocturnal cough [10], cold air as a cough trigger [4, 11, 12] and multiple triggers of cough [4]. These features may help physicians to recognise asthma as a potential cough background disorder, even among subjects lacking the classical asthma symptoms, namely shortness of breath and wheezing.

Sputum production was not statistically significantly associated with UACS or GORD in the present study. In a previous large Japanese study, both were statistically significantly associated with sputum production [13]. Different populations may explain this discrepancy. All subjects in the present study suffered from chronic cough, whereas the previous study investigated apparently healthy subjects. In our study, sputum production was more common in UACS and GORD than in unexplained chronic cough. Therefore, we think that the two studies are not conflicting.

The prevalence of sputum production was lowest among the subjects with unexplained chronic cough. A similar association has been reported earlier [14]. Furthermore, our study showed that the number of cough background disorders is associated with sputum production. These findings, alongside the findings of the previously mentioned Japanese study [13], suggest that the presence of sputum production in a patient with chronic cough should encourage a clinician to seek treatable cough background disorders especially carefully.

There are many shortcomings in the present study. The response rate was rather low, which is common in electronic surveys. However, this probably does not affect the main results of the present study. There were no elderly or unemployed subjects in the present population, which may decrease the generalisability of the results. GORD is difficult to recognise in a questionnaire study, since as many as $40-75 \%$ of subjects with GORD-associated cough do not exhibit the classic symptoms of GORD [15]. Thus, the number of GORD patients in the present population may be underestimated. The causative relationships between the background disorders and chronic cough are uncertain without confirmation by treatment response. All of the information used in the present analyses is based on self-reports in a cross-sectional design with the associated problems of biased reporting. The strengths of the present study include the large, unselected and well-characterised sample. The background disorders were clearly defined. Especially, the doctor's diagnosis of asthma in Finland is always based on objective evidence of variable airway obstruction [4].

\begin{tabular}{lccc}
$\begin{array}{l}\text { TABLE 1 Logistic regression analyses of the associations of the background disorders with } \\
\text { sputum production }\end{array}$ & Subjects $\mathbf{n}$ & Adjusted ${ }^{\#}$ OR (95\% Cl) & p-value \\
Disorder & 102 & $3.04(1.87-4.94)$ & $<0.001$ \\
\hline Current asthma & 157 & $1.32(0.88-1.96)$ & 0.18 \\
Upper airway cough syndrome & 113 & $1.24(0.80-1.92)$ & 0.34 \\
Gastro-oesophageal reflux disease & 144 & $0.54(0.36-0.81)$ & 0.003 \\
Unexplained chronic cough & 271 & $1.62(1.26-2.08)$ & $<0.001$ \\
Number of background disorders & &
\end{tabular}

For each disorder, the control group was those with chronic cough but without that background disorder. Several subjects had more than one background disorder. " : adjusted for current smoking; " : the number of background disorders was calculated as the sum of current asthma, upper airway cough syndrome and gastro-oesophageal reflux disease; the odds ratio was calculated per one background disorder. 
In conclusion, the presence of sputum production increases the probability of current asthma as the cough background disorder. It also increases the probability of multiple background disorders. Conversely, dry cough may suggest unexplained chronic cough. These findings may aid physicians in predicting the most probable cough background disorder.

Heikki O. Koskela $\oplus^{1,2}$ and Anne M. Lätti $\oplus^{1}$

${ }^{1}$ Unit for Medicine and Clinical Research, Pulmonary Division, Kuopio University Hospital, Kuopio, Finland. ${ }^{2}$ School of Medicine, Institute of Clinical Sciences, Faculty of Health Sciences, University of Eastern Finland, Kuopio, Finland.

Correspondence: Heikki O. Koskela, Unit for Medicine and Clinical Research, Pulmonary Division, Kuopio University Hospital, Kuopio, PL 100, 70029 KYS, Finland. E-mail: heikki.koskela@kuh.fi

Received: 2 Feb 2021 | Accepted: 13 March 2021

Acknowledgements: We thank Seppo Hartikainen, Istekki Ltd, Kuopio, Finland, for creating the electronic reply form and the data collection system.

Author contributions: Both authors made substantial contributions to the conception and design of the work; acquisition, analysis or interpretation of data for the work; and drafting the article or revising it critically for important intellectual content; and gave final approval of the version to be published; and agreement to be accountable for all aspects of the work, in ensuring that questions related to the accuracy or integrity of any part of the work are appropriately investigated and resolved.

Conflict of interest: H.O. Koskela reports nonfinancial support from AstraZeneca Ltd to attend the ERS International Congress 2018, payments for giving scientific lectures from Boehringer Ingelheim Ltd and ownership of stocks worth $€ 34000$ in Orion Ltd, outside the submitted work. A.M. Lätti reports grants from Kuopion Seudun Hengityssäätiö, Hengityssairauksien Tutkimussäätiö, Suomen Tuberkuloosin Vastustamisyhdistyksen Säätiö, Väinö ja Laina Kiven Säätiö and KYS Tutkimussätiö during the conduct of the study; and personal fees from Orion, Boehringer Ingelheim, Roche, AstraZeneca and Novartis to visit international scientific meetings, and consulting fees from GlaxoSmithKline, all outside the submitted work.

Support statement: This work was supported by the foundations Kuopion Seudun Hengityssäätiö and Hengityssairauksien Tutkimussäätiö. Funding information for this article has been deposited with the Crossref Funder Registry.

\section{References}

1 Morice AH, Millqvist E, Bieksiene K, et al. ERS guidelines on the diagnosis and treatment of chronic cough in adults and children. Eur Respir J 2020; 55: 1901136.

2 Mello CJ, Irwin RS, Curley FJ. Predictive values of the character, timing, and complications of chronic cough in diagnosing its cause. Arch Intern Med 1996; 156: 997-1003.

3 Spanevello A, Beghé B, Visca D, et al. Chronic cough in adults. Eur I Intern Med 2020; 78: 8-16.

4 Koskela HO, Lätti AM, Pekkanen J. Subfreezing air as a cough trigger and multiple triggers are strongly associated with the presence of asthma in chronic cough. Respir Med 2019; 153: 26-30.

5 Birring SS, Prudon B, Carr AJ, et al. Development of a symptom specific health status measure for patients with chronic cough: Leicester Cough Questionnaire (LCQ). Thorax 2003; 58: 339-343.

6 Definition and classification of chronic bronchitis for clinical and epidemiological purposes. A report to the Medical Research Council by their Committee on the Aetiology of Chronic Bronchitis. Lancet 1965; 285: 775-779.

7 Fokkens WJ, Lund VJ, Mullol J, et al. European position paper on rhinosinusitis and nasal polyps 2012. Rhinology 2012; 50: Suppl. 23, 1-298.

8 El-Serag HB, Sweet S, Winchester CC, et al. Update on the epidemiology of gastro-oesophageal reflux disease: a systematic review. Gut 2014; 63: 871-880.

9 Colak Y, Afzal S, Lange P, et al. Role and impact of chronic cough in individuals with asthma from the general population. J Allergy Clin Immunol Pract 2019; 7: 1783-1792.e8.

10 Fukuhara A, Saito J, Birring SS, et al. Clinical characteristics of cough frequency patterns in patients with and without asthma. J Allergy Clin Immunol Pract 2020; 8: 654-661.

11 Kanemitsu Y, Matsumoto H, Osman N, et al. "Cold air" and/or "talking" as cough triggers, a sign for the diagnosis of cough variant asthma. Respir Investig 2016; 54: 413-418.

12 Matsumoto H, Tabuena RP, Niimi A, et al. Cough triggers and their pathophysiology in patients with prolonged or chronic cough. Allergol Int 2012; 61: 123-132.

13 Morimoto C, Matsumoto H, Nagasaki T, et al. Gastroesophageal reflux disease is a risk factor for sputum production in the general population: the Nagahama study. Respir Res 2021; 22: 6 .

14 Choudry NB, Fuller RW. Sensitivity of the cough reflex in patients with chronic cough. Eur Respir J 1992; 5: 296-300.

15 Hom C, Vaezi MF. Extraesophageal manifestations of gastroesophageal reflux disease. Gastroenterol Clin North Am 2013; 42: 71-91. 